\title{
Agomelatine: relief ensured at each and every stage of depression
}

\author{
Hans-Jurgen Möller \\ From $1^{\text {st }}$ International Congress on Neurobiology and Clinical Psychopharmacology and European \\ Psychiatric Association Conference on Treatment Guidance \\ Thessaloniki, Greece. 19-22 November 2009
}

In the recent years the aim of drug therapy in depression was redefined and specified. According to this, the main goal of antidepressant treatment goes beyond achieving some degree of response, or full response in the sense of $50 \%$ reduction of a depression score, but to remission in the global sense as well as on a more differentiated level, which means almost complete relief of depressive symptoms or at least almost complete relief of the core or most relevant symptoms of depression. This redefinition of the major therapeutic goal of antidepressive treatment was necessary, because several longterm studies demonstrated, that only remission and in this context the relief of the core or most relevant symptoms of depression can guarantee with a reasonably high probability a positive outcome under longterm aspects. The presentation will focus especially on the issue of relief of the core or the most relevant symptoms of depression and the respective efficacy of drug treatment with the recently licensed antidepressant agomelatine. Traditionally, especially depressed mood and lack of interest were seen as the core symptoms of depression. This is also mirrored in the current diagnostic manuals. However, considering the frequency and clinical relevance of sleep disturbances, and interpreting this in the context of the aetiopathogenetic hypothesis of disturbed circadian rhythm, sleep disorders can be interpreted as a core symptom in another sense. The same might be true for anxious symptoms, given the high neurogenetic association of depressive and anxious symptoms.

Agomelatine has demonstrated powerful antidepressive efficacy, amongst others in terms of improvement of depressive mood and in terms of remission. According to its neurobiological mood of action, agomelatine

Psychiatric Department, Ludwig-Maximilians University, Munich, Germany has a special efficacy focus on disturbances of circadian rhythms and demonstrates clinical efficacy in this respect. Given the high frequency of anxious symptoms in depression and the comorbidity between depression and anxiety disorder, the efficacy of agomelatine in anxious symptoms also seems to be a beneficial aspect of the efficacy profile.

Taken together, these findings show that agomelatine qualifies as an efficient option in the treatment of depression based on its broad efficacy on the full spectrum of depressive symptoms, including those occurring early as well as those that tend to persist late over the course of the disorder.

Published: 22 April 2010

\section{doi:10.1186/1744-859X-9-S1-S49}

Cite this article as: Möller: Agomelatine: relief ensured at each and every stage of depression. Annals of General Psychiatry 2010 9(Suppl 1): S49.

\author{
Submit your next manuscript to BioMed Central \\ and take full advantage of: \\ - Convenient online submission \\ - Thorough peer review \\ - No space constraints or color figure charges \\ - Immediate publication on acceptance \\ - Inclusion in PubMed, CAS, Scopus and Google Scholar \\ - Research which is freely available for redistribution \\ Submit your manuscript at \\ www.biomedcentral.com/submit
}

